\title{
Study on the Connotation of Holistic Design Associated with De Stiji Architecture and Furniture
}

\author{
Fu Xiao-li ${ }^{1}$, Dai Zhi-yong ${ }^{2}$ \\ ${ }^{1}$ Xiamen Institute of Technology, Architecture Department, 361021 XiaMen, China \\ ${ }^{2}$ Yangshi Planning \& Architecture Design CO., LTD, 361021 XiaMen, China
}

\begin{abstract}
The modern furniture has been closely linked to architecture since its inception. There is an intrinsic correlation between furniture and architecture in Schröder House, which is designed by Gerrit Rietveld who is one of the masters of De Stiji architecture. The architectural space is constructed based on the design vocabulary of 'architectural furniture'. On the contrary, the furniture design presents the characteristics of "furniture building". The article tries to assay the history between Schröder House and De Stiji, the characteristics of the epoch, and combined with Gerrit Rietveld's design thought and related works, it analyzes the integration between furniture and architecture from the angles of structural system based on scaffolding, spatial ratio based on golden segmentation, colour system based on t primary colours in Schröder House.
\end{abstract}

\section{Introduction}

There is a close internal relationship between modern architecture and furniture. It stems from the overall artistic concept in the modern sense which is advocated by Joseph Hoffman and Otto Koloman Wagner: the furniture should be integrated into the context of architectural space for overall design. Schröder House is considered to be the representative work of De Stiji, which not only embodies the characteristics of 'whole art' advocated by Hoffman, but also reflects the interaction between modern Western furniture and De Stiji architecture in the early 20th century. The red-blue chair has an epoch-making important position in the history of modern furniture development. With the distinctive modern form, it was finally freed from the influence of traditional style furniture and became the prophecy of independent modernist trend [1]. Schröder House (1925) was influenced by the design concept of the red-blue chair, and Rietveld once said: "When I got the opportunity to design a house with the aesthetic principles of the red-blue chair, I eagerly grasped it."[2] There is a close correlation between furniture and architecture in Schröder House, which embodies the ideological connotation of 'holistic-design'.

\section{Structural features based on scaffolding}

Rietveld as a true craftsman, he is more guided by the mind of carpentry than as an architect [3]. In the conceptual sketch of Schröder House drawn by Rietveld (Fig. 1), we can see that the structural connection within the balcony is much like 'scaffolding', which is very similar to the nodes of the red-blue chair (Fig. 2). The scaffolding tied up with ropes aroused Rietveld's interest, which made him come up with the wooden frame that was interconnected to each other in the red-blue chair. It's a starting point for connecting architecture to furniture.

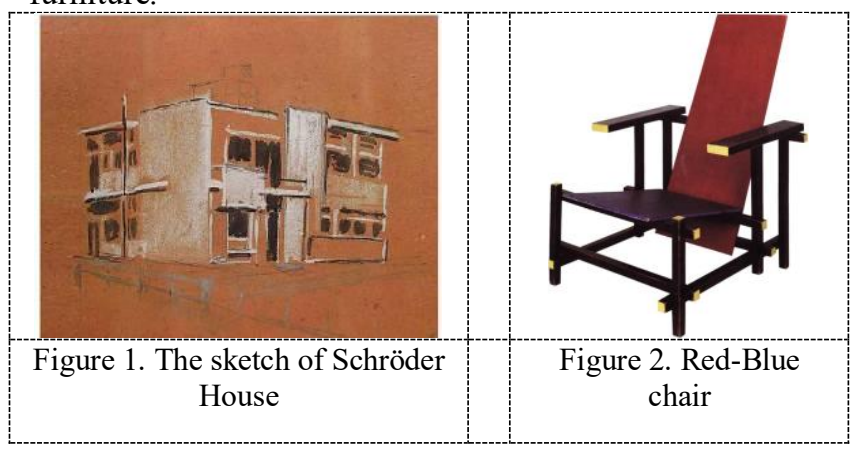

\subsection{Structural features of furniture}

As the internal logic of furniture design, furniture structural design has its own rationality and technical aesthetics. The structural node of 'scaffolding' within the red-blue chair reflects the aesthetic characteristics of De Stiji and has roughly gone through the following stages: in 1908, Rietveld designed an armchair with a frame structure and connected by the dowel. The shape of this chair is very simple, and the intersection of structural components is also very regular; the drawing table designed in 1915, still used a frame structure, which connected two transverse braces with the longitudinal component at the lower part of the table leg, and it enhanced the stability of its overall structure; for the first 
time, the playpen designed in 1918 showed the structural form of 'scaffolding', and its horizontal and vertical components were connected by non-coplanar bonding. At the corner, three horizontal components began to intersect at one dot (heterogeneous), and the components broke through the limits of the intersecting plane, and extended a short distance in their respective directions; for the first time, yellow colour was used in the cross section of linear components in child's chair designed in 1918 to imply the independence and spatial ductility of the components. The two horizontal components within the node broke through the limits of the vertical intersecting surface, but the ends of each other were intersected vertically; the node features of the 'scaffolding' in the Sideboard and upright chair designed in 1918-1919 had been established, since then, the works of the red-blue chair series followed the feature; a new attempt was made in the cupboard and Berlin Chair designed in 1923 based on the 'scaffolding' node. The asymmetric composing form was adopted, and the linear component was replaced by the plate, thus it formed a new box-frame structure.

The types of furniture in Schröder House are mainly divided into movable furniture and stationary furniture. Among them, the removable furniture are the previous works designed by Rietveld, mostly using frame structure and the'scaffolding' structural nodes, and they are placed in the prominent position to highlight their dominant effect in space. Fixed furniture has obvious characteristics of "furniture-architecture": through the structural nodes (scaffolding) and architectural components to form an organic whole, for example: embedded wardrobe, embedded locker, fixed seats for inlet accessories, etc.

\subsection{Structural features of architecture}

Schröder House uses the brick-masonry structure: its structural components are mainly composed of wooden grille, 'I' steel beams, brick walls, concrete balcony panels, 'I' steel columns. Comparing it with the box structure system of the Berlin Chair, we can find that there are very similar characteristics: asymmetric geometrical composition, the corner is supported by linear components. The structural components of the convex balcony have very obvious 'scaffolding' structural features: yellow 'I' steel columns, blue 'I' beams, white horizontal plates intersect at one point and continue to extend some distance along their original direction. In addition, this structural feature exists in the door frames and window frames in the façade of the building, and in the railings of the indoor staircase.

\section{Spatial ratio based on golden segmentation}

The existence of architecture and furniture need to occupy the certain space. The building creates space through the encirclement of the interface, while the furniture embodies the practicality by shaping the space. Space becomes the link between furniture and architecture, while furniture is the medium and carrier that connects architecture with space and it has a direct connection with humans. The spatial modulus based on the golden segmentation becomes the link between furniture and architecture in Schröder House. This kind of design method which emphasizes concise geometry and spatial proportion is influenced by 'neoplasticism'. The term 'neoplasticism' derives from the writings of the Dutch philosopher M.H Shernmarks, who claims that people can use meditation to understand nature and to perceive the inner structure of things. Mondrian explained it in another way: "through pure scientific means, we can achieve the purpose of human practicality, but also through more abstract pure artistic means, to give us a similar contribution to life."[4] Since 1917, Mondrian has created a series of graphic design works based on the proportional relationship of golden segmentation. There is also a wide range of applications similar to the golden division in Schröder House.

\subsection{The proportion of golden segmentation in Schröder House}

The length and width of Schröder House is about $13 * 8 \mathrm{~m}$, and its aspect ratio is about 1.600 , which is very close to the golden segment ratio of 1.618. There are a large number of golden dividing lines in the plane (Fig. 3). One of the most obvious golden dividing lines (red diagonal): starting from the corner of the balcony at the bottom right of the building plane, through the corner of the balcony door, the corner of the removable partition wall, the corner of the upper left of the staircase, and it has been extended to the 'I' load-bearing steel column near the corner window of the restaurant. The golden dividing line in the plane is similar to 'positioning coordinates', which determines the corner position of architectural components and embedded fixed furniture. In the façade of Schroeder's house, there is also a spatial limitation relationship based on the Golden segmentation ratio: the vertical and horizontal positions of doors, windows, railings and walls, and the corner of the space, are strictly limited by the golden dividing lines (Fig. 4). 


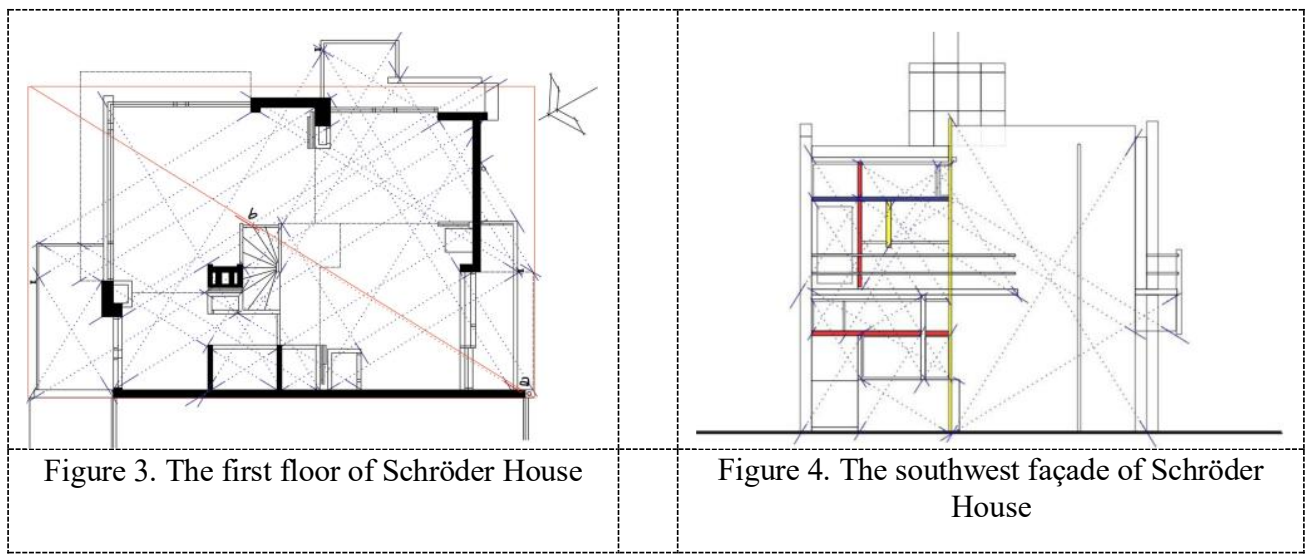

\subsection{Architectural attributes of Furniture}

The golden dividing line in Schröder House is also used to limit and organize the spatial relationship between furniture and architecture, which makes the furniture show a kind of 'furniture-architecture' characteristics: the furniture has its own function of use, but also participates to the construction of architectural geometric space order; the location of furniture is precisely defined. For example, in the plan of first floor (Fig. 5): first, the core of the planar space-stairwell (red filling area), is limited by the golden rectangle, and then the right end of the sofa bed at the lower right entrance is limited by the stairwell (blue dotted line); the position of the right boundary and removable partition of the architecture is limited by the golden rectangle (yellow filling area) which is connected to the top of the stairwell, and then the positioning shaft (purple dotted line) which on the right side of the table is limited by the golden rectangle (blue Fill area); the end of the stairwell is connected to a golden rectangle (green fill area), which limits the boundary of the bottom of the plane; a golden rectangle (green fill area) is attached to the left side of the positioning axis on the right side of the table (yellow dotted line). Another important role of the golden dividing line is to establish a visual connection between furniture and architecture in real space, and create a balanced, harmonious and enjoyable visual effect. Salgado redrawn it into an internal perspective rendering based on the drawings which Rietveld drew (Fig. 6): we realized that the observer's sightline almost coincides with a golden line [5].

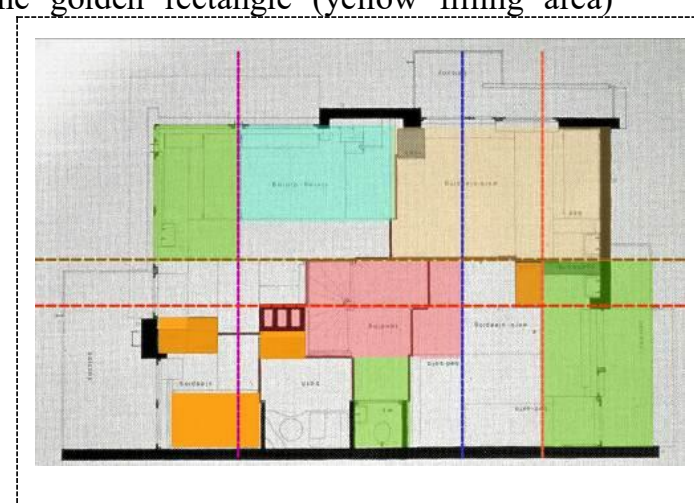

Figure 5. The analysis diagram of first floor of Schröder House

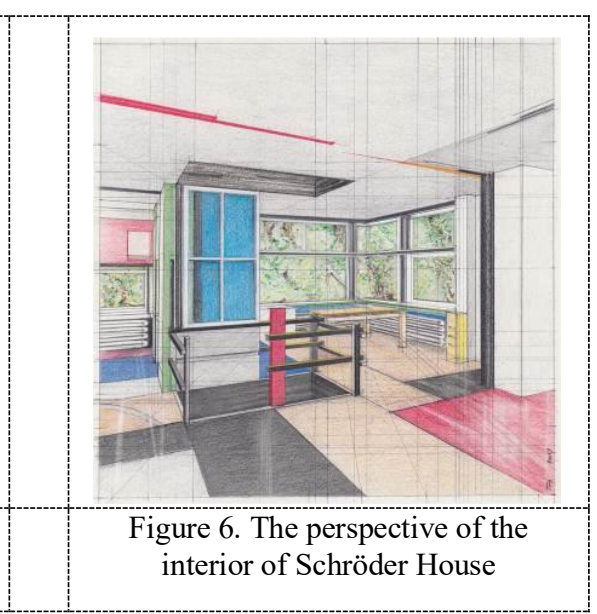

elements of these theories and their geometric expressions. Doesburg suggested that: the equilibrium of architectural relationships first becomes visible reality through colour. The modern painter's task is to organise this into a harmonious whole (not in a plane, not in two dimensions, but in the new field: four-dimensional timespace) [7]. On the contrary, Rietveld argued that Architects should be allowed to dominate the concept of architectural design and chose the right colour system as the conceptual basis for space creation. 


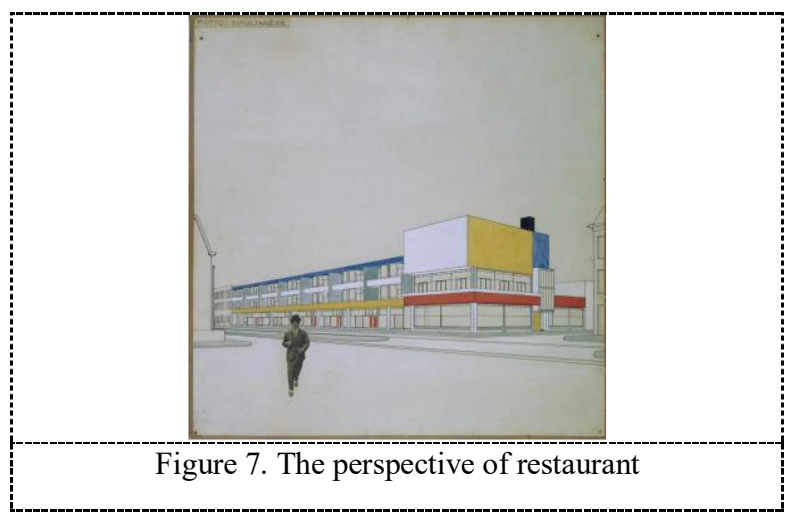

The colour principle of De Stiji is primary colour and non-colour. The colour system and operation method of furniture and architecture are consistent in Schröder House, which are based on the aesthetic principles of De Stiji: the interface of the component uses primary and non-colours; the section at the end of the component uses the primary colour to imply its spatial continuity; different colours are given to the components according to their different functions to highlight their independence. Rietveld's method of colour expression is very different from that of other De Stiji architects. Comparing the rendering of the coffee restaurant drawn by Doesburg in 1924(Fig. 7): the structural components are painted in a single colour and arranged in a very regular way. For example: load-bearing columns use white, load-bearing walls use grey, and non-load-bearing components use primary and non-colour, and their decorative nature is implied by the diversity of their colours and the irregular spatial location. This colour system emphasizes the dominant position of structural elements in architectural space, and establishes the hierarchical order of traditional architectural space. In contrast, the colour system in Schröder House is the overall design of architecture and furniture, which is a kind of "anti-grade" and "anti-traditional" space manipulation. Rietveld is able to privilege the abstract relationships of vertical and horizontal planes uninhibited by the necessity to respond to their traditional architectural character [8]. It emphasizes the equality between different spatial elements: the core of the living space-fireplace (building) and coffee table (furniture) are blue, staircase column (building) and the red-blue chair's backrest (furniture) are red, 'I' steel column (loadbearing) and window lattice (non-load-bearing) are yellow and so on. The floor of the interior space is also made of primary and non-colour to establish the visual connection between the furniture and the architectural space, and form an organic whole.

\section{Conclusions}

In every era, there are different degrees of interaction between furniture and architecture. The red-blue chair is the material representation of the idea of De Stiji, and it is also the starting point of Schröder House. At the same time, the furniture presents the characteristics of architecture. Furniture and architecture have a high degree of integrated design characteristics in Schröder House, such as the structure of the system, space ratio, colour system, design concepts and so on. The design method has the value of important reference and inspiration for constructing the holistic design concept of contemporary furniture and architectural space.

\section{References}

1. Hu Jing-chu. (2005) History of mordern furniture in the world. Central Compilation \& Translation Press, Peking.

2. Paul Overy. (1988) The Rietveld Schröder House. MIT Press, Cambridge.

3. García Salgado. (2018) The Rietveld-Schro"eder house and the fifth element. Nexus Netw J., 20: 417-435.

4. Abdulaziz AL-Saati. (1990) Mondrian: neoplasticism and its influences in architecture. METU JFA., 10: 63-74.

5. García Salgado. (2018) The Rietveld-Schro“eder house and the fifth element. Nexus Netw J., 20: 417-435.

6. H. Minkowski, 'Raum und Zeit', op. cit., pp. 7588.

7. J. Baljeu, Theo van Doesburg, op. cit., p. 187.

8. Desley Luscombe. (2012) Illustrating architecture: the spatio-temporal dimension of Gerrit Rietveld's representations of the Schröder House. The Journal of Architecture., 18: 25-58. 